IOSR Journal of Engineering

May. 2012, Vol. 2(5) pp: 1095-1101

\title{
HVDC Transmission with STATCOM
}

\author{
Ashish Dewangan ${ }^{1}$, Dr. Rn pate ${ }^{2}$ \\ Department of Electrical Engineering, Shri Shankara College of Engineering \& Technology \\ Bhilai-490020, Chhattisgarh, India
}

\begin{abstract}
Most of the HVDC power converters with thyristor valves are assembled in a converter Bridge of Six pulse configuration. Converter transformers with one DC side winding as an ungrounded star connection and the other a delta configuration. Comparative studies of the two systems of HVDC CIGRE model without STATCOM and with STATCOM were performed. In these case, the consideration was the converter transformer saturation, which results in voltage and current distortion at the inverter end and Rectifier End. Results with certain fault cases-with either 1-phase, 3-phase and Dc fault at the inverter end and rectifier end are presented. (i.e., taken from CIGRE model) Power Quality analyzed both at rectifier and inverter end after the fault and the types of fault taken in to considerations are: 1 ) L-G fault, 2) L-L-G fault, 3) DC fault. This should be compared where the corresponding case with the STATCOM in place is depicted. In this project work, a HVDC transmission line from CIGRE model sending end and receiving end power having 100MVA. The DC line is approximately $100 \mathrm{~km}$ long and is connected to the 100MVA system through two converter transformers, one of them with wye (grounded)/delta configuration, and the other with delta / wye (grounded) configuration at each end, from the simulation results, it has been shown that the voltage profile analysis can be done by using PSCAD/EMTDC software.
\end{abstract}

Keywords: HVDC transmission, STATCOM.

\section{INTRODUCTION}

DC converters inherently consume large amounts of reactive power. Normally, the reactive demands of the converter are $50 \%$ to $60 \%$ of the DC power being transferred. For the design and operation of six pulse HVDC using linecommutated thyristor converters, connected to AC networks, the special concerns in case of connecting in weak AC system are needed following as; high temporary overvoltage (TOV), low frequency resonances, risk of voltage instability, harmonic instability, long fault recovery times and increased risk of commutation failure[1]. Many of the above phenomenon is closely related to the $\mathrm{AC}$ voltage regulation at the converter bus. The adequate types of voltage regulation under the case of these are the synchronous compensator (SC), the SVC (Static Var Compensator) and the STACOM (Static Synchronous Compensator). Until now, HVDC and reactive compensators was operated and controlled independently. And the interactions between HVDC filter and reactive power compensator were only considered in steady state [2]. If the coordination between six pulse HVDC and reactive power compensator is possible, the performance of HVDC will be improved in transient state.

\section{PROBLEM DEFINITION}

The six-pulse converter bridge used as the basic converter unit of HVDC transmission rectification where electric power flows from the ac side to the DC side and inversion where the power flow is vice versa. At present, six pulse HVDC system with FACTS devices (especially STATCOM) considered to be most promising among other pulse $(12,24$ etc.) system [1]. Because of the growing interest in this area, quite a number of papers have reported on different aspect of power transmission technology with power quality. Here power quality is main concern .In addition to the analysis, modeling, including fault analysis, of six pulse HVDC system with STATCOM have been carried out.

\section{PROPOSED HVDC-STATCOM SYSTEM}

Figure 1.1, shows high voltage Dc transmission using STATCOM connected at the inverter side, these are one of the devices of the FACTS family. It exhibits a property of mitigation of sag, swell and notches. It provides better power flow control.And also improve the power transfer capability in a high voltage transmission line[2]. Normally due to line charging, and also due to thyristor switching at converter end, certain harmonics and voltage sag, swell takes place. so it directly affect the power quality, and reaches to the receiving end, and this poor quality power is given to the load, which leads to the malfunctioning and inefficient performance of the system. If STATCOM is connected at the receiving end before the load then in case of any voltage instability or any fault. The severity and quality is mitigated. So thereby increasing the power quality [3]. And in today's arena power quality is main concern. In this Figure firstly 
IOSR Journal of Engineering

May. 2012, Vol. 2(5) pp: 1095-1101

AC supply is provided by alternator, and by means of (usually three phase) transformer voltage level is rectifier converter (thyristor combination, in this thesis 6 pulse is adopted), so before feeding to the rectifier it is called HVAC (high voltage AC transmission). And by rectifier DC output is taken, and it is called as a Dc link. This Dc supply is inverted by means of Inverter (which is a 6pulse arrangement of thyristor). And after getting Ac output from inverter, this is again fed to the STATCOM for mitigation.

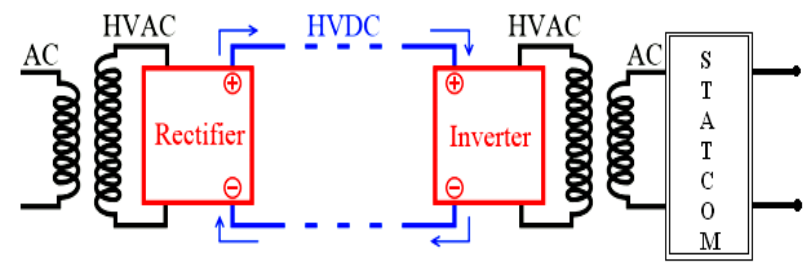

Figure 1.1 HVDC with STATCOM transmission system

Before restarting the system, it will be necessary to disconnect the load from the HVDC inverter. The STATCOM is precharged to supply the power to HVDC system through the small generator and a rectifier. The DC capacitor continues to be fed by the auxiliary power supply until the HVDC converter starts. When the DC capacitor is fully charged, the STATCOM output voltage is ramped up (giving smooth energization of the transformer) and then the HVDC converter can be deblocked to commence transmitting active power. After HVDC system has recovered, the disconnector switch is opened to isolate the auxiliary power supply to the DC capacitor of the STATCOM. Short term active power variation can be buffered and together with the reactive power disturbances to the main grid can be mitigated effectively.

\section{A. STATCOM [4]}

A static synchronous compensator (STATCOM), also known as a "static synchronous condenser" ("STATCON"), is a regulating device used on alternating current electricity transmission networks. It is based on a power electronics voltage-source converter and can act as either a source or sink of reactive $\mathrm{AC}$ power to an electricity network. If connected to a source of power it can also provide active AC power. It is a member of the FACTS family of devices. Usually a STATCOM is installed to support electricity networks that have a poor power factor and often poor voltage regulation. There are however, other uses, the most common use is for voltage stability.

The $V$ - $I$ characteristic of the static compensator shown in Figure 2.1 represents a steady-state relationship.

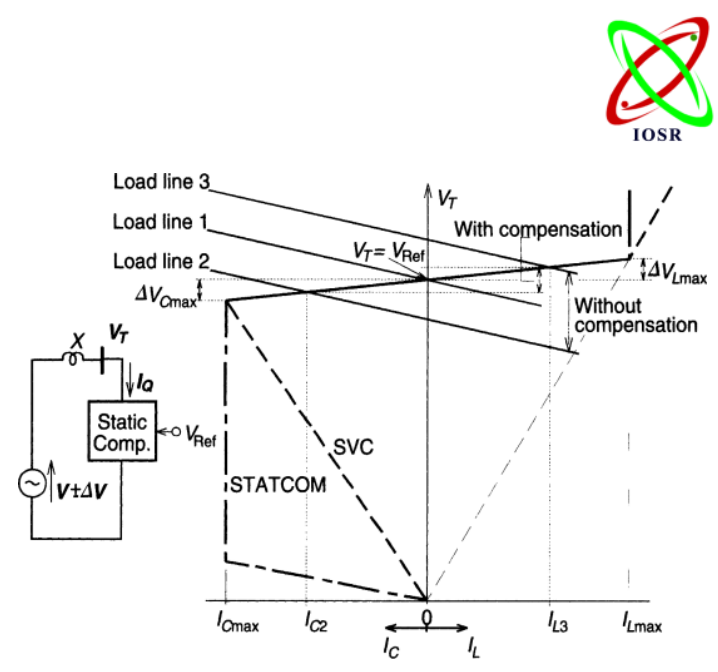

Figure 2.1 V-I characteristic of the SVC and the STATCOM.

The dynamic behavior of the compensator in the "normal compensating range can be characterized by the basic transfer function block diagram shown in Figure 2.2. In the linear operating range of the compensator, the terminal voltage $\mathrm{V}_{\mathrm{T}}$ can be expressed from Figure 3.14 in terms of the internal voltage $V$ and the reference voltage $V_{\text {Ref }}$ as follows:

$$
V_{T}=V \frac{1}{1+G_{1} G_{2} H X}+V_{\text {Ret }} \frac{G_{1} G_{2} X}{1+G_{1} G_{2} H X}
$$

Since the objective is to establish how well the terminal voltage is regulated

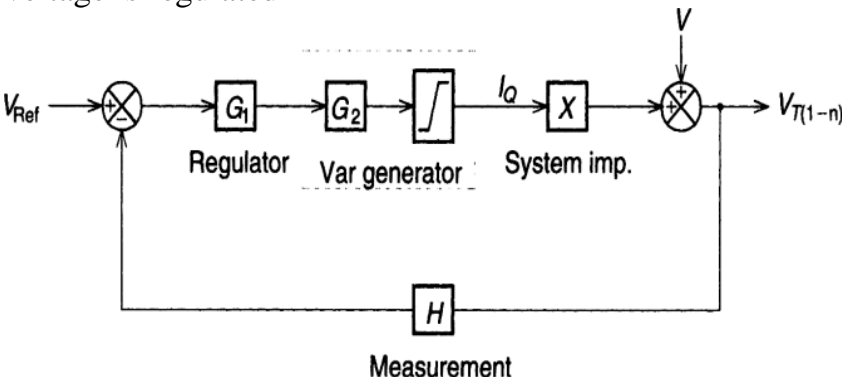

Figure 2.2 Basic transfer function block diagram of the static (var) compensator.

Against the (varying) system voltage, let $\mathrm{V}_{\mathrm{Ref}}=0$ and consider small variation only. Then the amplitude variation of the terminal voltage $\Delta \mathrm{v}_{T}$ against the amplitude variation of the power system voltage $\Delta \mathrm{V}$ can be expressed in the following form:

$$
\frac{\Delta V_{T}}{\Delta V}=\frac{1}{1+G_{1} G_{2} H X}=\frac{1}{1+G H X}
$$

$$
G_{1}=\frac{1 / \kappa}{1+T_{1} s}
$$

And, 
IOSR Journal of Engineering

May. 2012, Vol. 2(5) pp: 1095-1101

$$
\begin{aligned}
& G_{2}=e^{-T_{d} s} \\
& G=G_{1} G_{2}=\frac{1 / \kappa}{1+T_{1} s} e^{-T_{d} s} \\
& H=\frac{1}{1+T_{2} s}
\end{aligned}
$$

and $\mathrm{T} 1$ = main time constant of the PI controller (typically about $10-50 \mathrm{~ms}$ depending on the var generator transport lag), $T 2=$ amplitude measuring circuit time constant (typically about 8-16 ms), $T_{d}=$ transport lag of the var generator (typically $2.5 \mathrm{~ms}$ for TCR, $5.0 \mathrm{~ms}$ for TSC and 0.2-0.3 ms for converter), $\quad X=\mathrm{I}_{\mathrm{m}} \mathrm{Z}$ (reactive part of the system impedance), $\mathrm{K}=$ regulation slope (typically $1-5 \%$ ) given by (5.15), and $s=$ Laplace operator. It should be pointed out "that practical compensator controls often employ filters in the signal processing circuits which may introduce additional time constants in the transfer functions affected. Sometimes phase correcting (lead / lag) circuits are also employed. Under steady-state conditions $(s \rightarrow 0)$, equation (2) becomes,

$$
\frac{\Delta V_{T}}{\Delta V}=\frac{1}{1+\frac{X}{x}}
$$

Equation (7) confirms that as the slope becomes smaller ( $\mathbf{K}$ $\rightarrow \mathbf{0}$ ), the terminal voltage remains constant, independent of the system voltage variation $\left(\Delta \mathbf{V}_{\mathbf{T}} / \mathbf{\Delta V} \rightarrow \mathbf{0}\right)$. Similarly, with increasing slope $(\mathbf{K}>>\mathbf{X})$ the terminal voltage becomes unregulated $\left(\Delta \mathbf{V}_{\mathbf{T}} / \mathbf{\Delta} \mathbf{V} \rightarrow \mathbf{0}\right)$. It is to be noted too that (2) defining the dynamic behavior of the compensator is a function of the power system impedance, that is, the system impedance is an integral part of the feedback loop.

\section{B. Test System}

This thesis based on CIGRE model data, in which sending end and receiving end power is 100MVA, having same frequency $60 \mathrm{~Hz}$ at both side [5]. Out of FACTS devices, STATCOM has been taken in to consideration, by using STATCOM at the receiving end power quality is analysed both at favourable and non favourable condition. So the role of STATCOM is to improve the voltage profile for better utilization of existing power system, before connecting STATCOM at the receiving end the voltage profile has been compared.
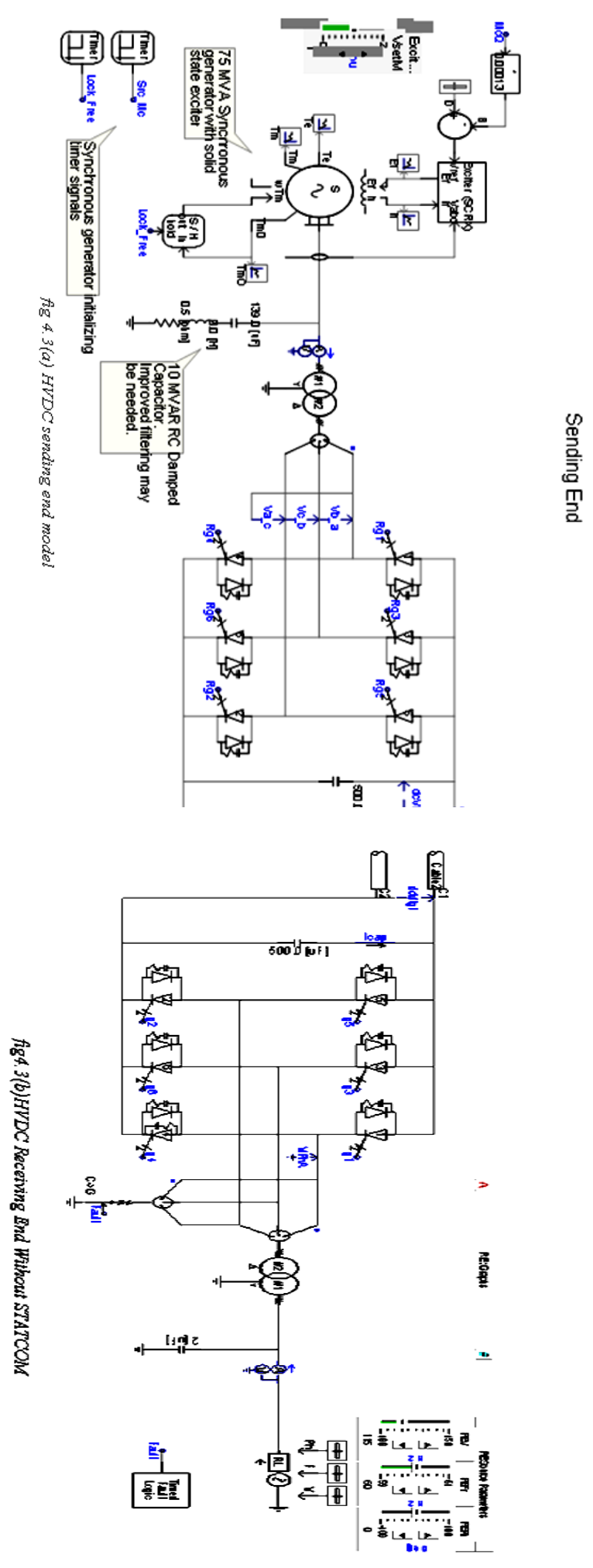
The Figure 4.7 shows the interface of a transmission line to the circuit model.

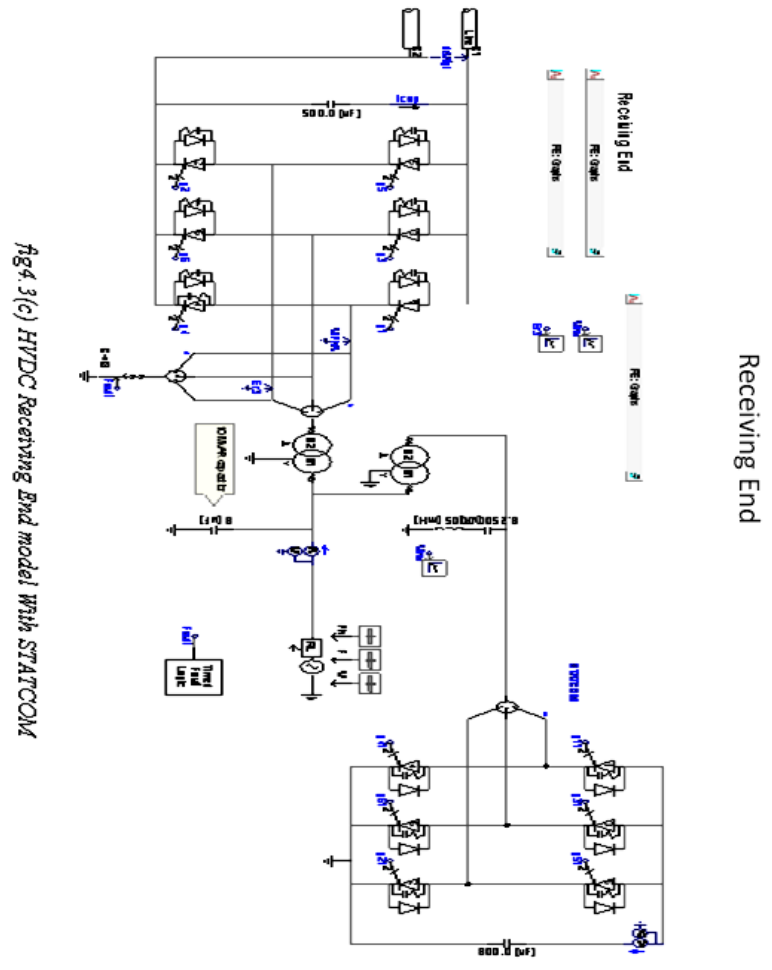

\section{Synchronous Machine modelling}

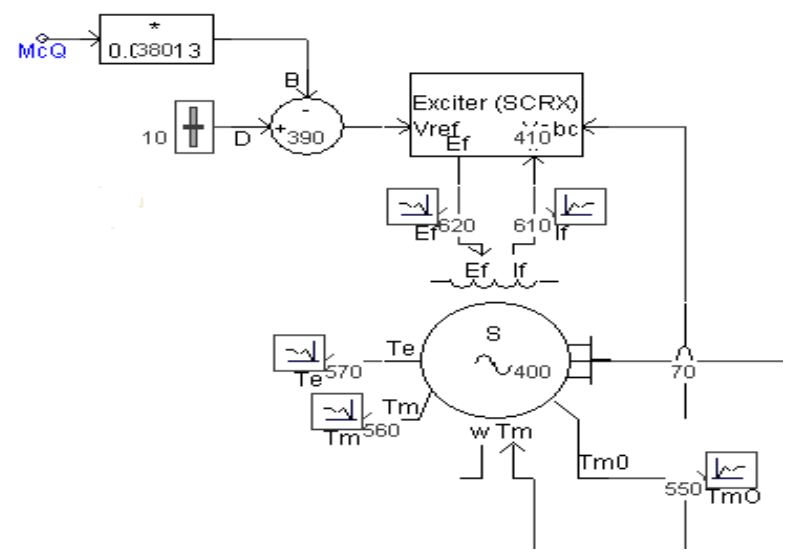

Figure 4.1 Synchronous machines in PSCAD

\section{DC line modelling}

Modelling of Transmission lines in PSCAD is very easy if we have all the data [6-7]. This data includes the conductor type the tower data and the length of the Transmission line.

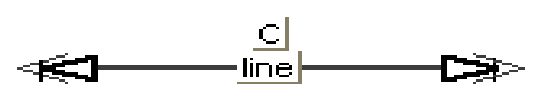

Figure 4.7 DC Line

\section{E. Transformer Modelling}

The transformer interface in PSCAD is given in Figure 5.1

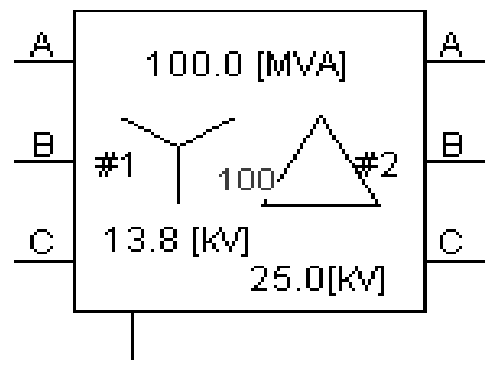

Figure 5.1 Transformer model in PSCAD

\section{F. Statcom Modelling}

STATCOM (Static Compensator) has a characteristic similar to the synchronous condenser, but as an electronic device, it has no inertia and is superior to the synchronous condenser in several ways - better dynamics, a lower investment cost, and lower operating and maintenance costs. STATCOM is to be selected when the technical performance in a specific application so requires. However, utilizing thyristors with turn-off capability (GTO or IGBT), which is the common approach in the industry, does not allow the full potential of a STATCOM concept to be obtained. Figure 6.1 shows the modeling of STATCOM.

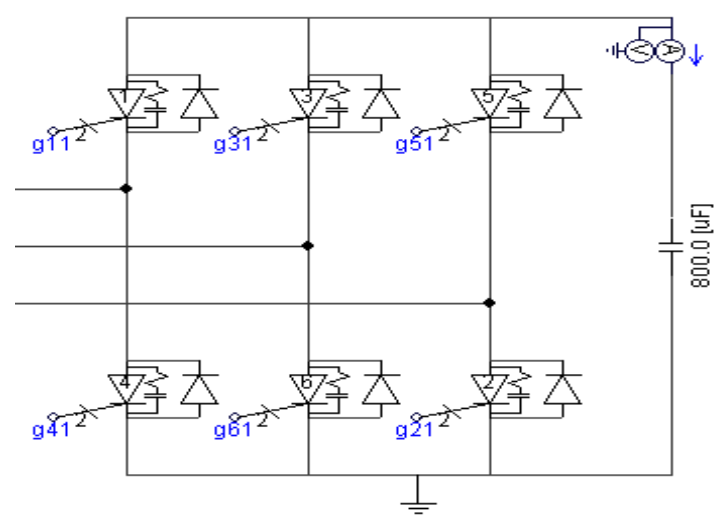

Figure 6.1 STATCOM model in PSCAD 


\section{Simulation Results}

A.Charging of HVDC line with and without STATCOM .In an six pulse HVDC system, during charging of the line, due to power swing at starting, the voltge magnitude goes to high valve for transient period (at about 0.5 seconds) and becomes some what constant after this period, Figure 7.1(a) represents the dc link voltage waveform both at rectifier end and at inverter end, without connecting STATCOM at the receiving end at normal condition. And Figure 7.1(b) represents the dc link voltage waveform with connecting STATCOM at the receiving end during normal condition .

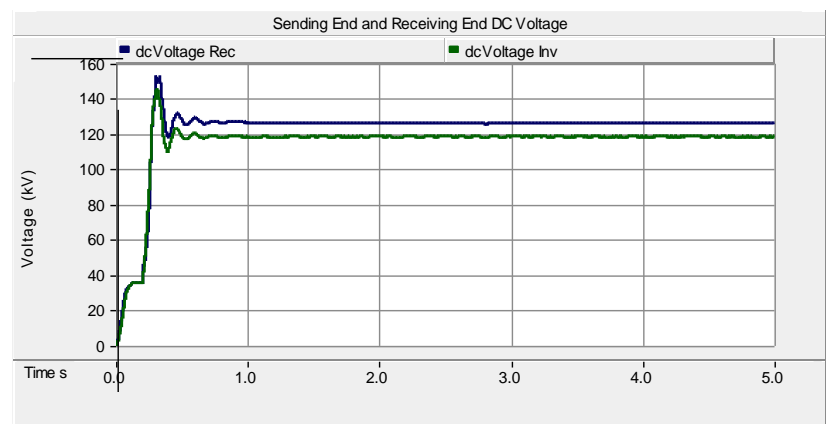

Figure7.1 (a) DC voltage waveform at the time of line charging, without STATCOM

On comparing Figure 7.1(a) and (b), Blue line shows rectifier end waveform and green colour line shows inverter end waveform, it is found that there is a certain amount of harmonics and voltage drop in Figure 7.1(a), and after connecting STATCOM in Figure 7.1 (b). This shows more stable waveform.

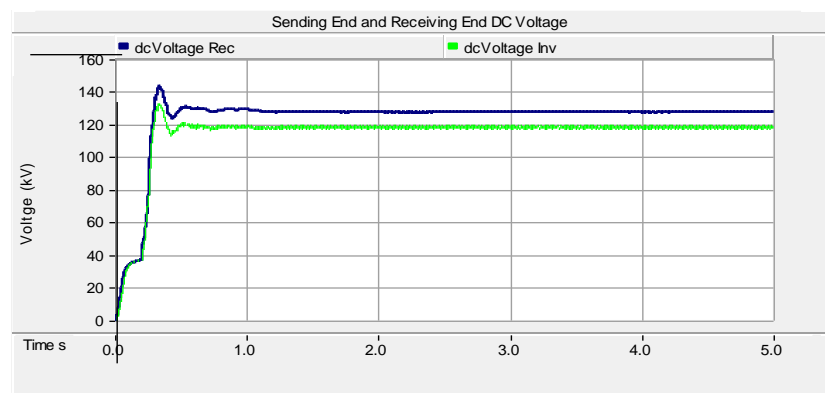

Figure7.1 (b) DC voltage waveform at the time of line charging, with STATCOM

\section{Fault Analysis in HVDC line with and without STATCOM}

a) When single Line to ground fault (L-G) occurs :

When single line to ground fault occurs at receiving end ,i.e., at inverter end of HVDC, from Figure 7.2(a) without connecting a STATCOM, there is voltage swell at after 2.1 seconds thereby amplitude reaches to a high value (more than $140 \mathrm{kv}$ at positive half and more than $80 \mathrm{kv}$ at negative half) and

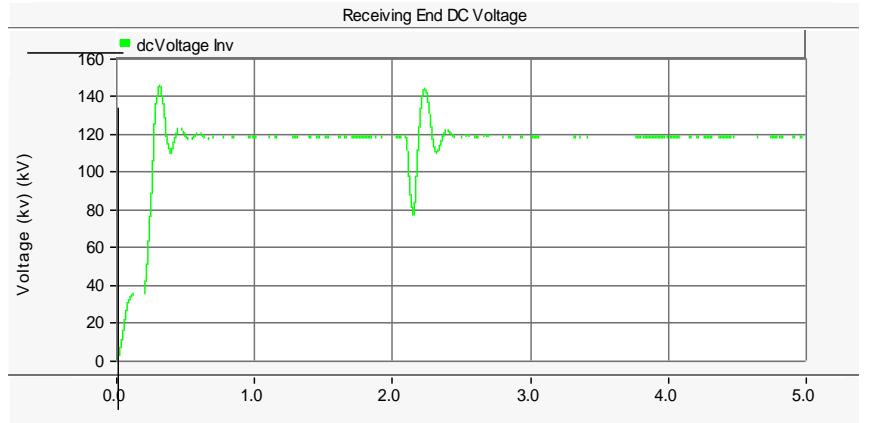

Figure7.2 (a) DC voltage waveform at the time of L-G fault, without STATCOM

in Figure 7.2(b), with STATCOM, it mitigates the voltage swell largely, in this the value of amplitude is less than the previous one (at about 40 percent i.e., $135 \mathrm{kv}$ at positive half and $78 \mathrm{kv}$ at negative half) and after this fault duration ,voltage becomes constant.

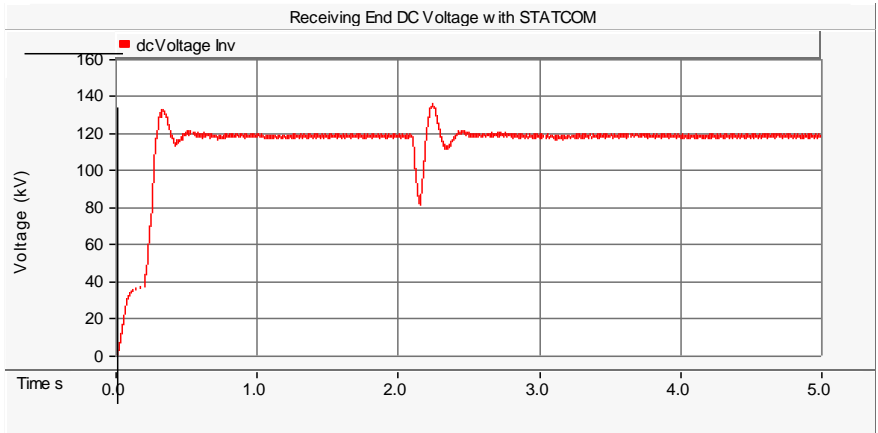

Figure 7.2(b) DC voltage waveform at the time of L-G fault, with STATCOM

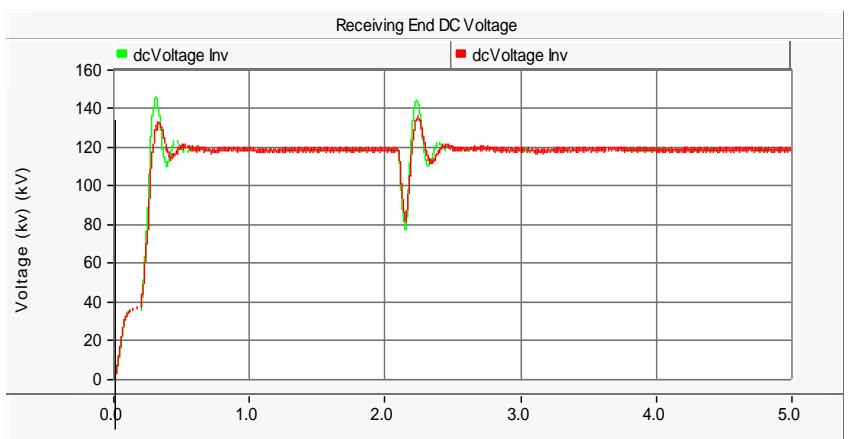

Figure 7.2(c) DC voltage waveform at the time of L-G fault, with and without STATCOM 
Figure 7.2(c) represents the comparison of Receiving end Figure 7.2(a)and Figure7.2 (b),It is clearly seen with the help of merged graph ,that the green colour waveform shows the effect of without STATCOM and red colour waveform shows effect of with STATCOM and and after connecting STATCOM system is highly stable, also the voltage profile changes, and that changes is appreciable.

When single line to ground fault occurs at sending end ,i.e., at rectifier end of HVDC, from Figure 7.2 (d) without connecting a STATCOM, there is voltage swell at after 2.1 seconds thereby amplitude reaches to a high value (more than $140 \mathrm{kv}$ at positive half and more than $75 \mathrm{kv}$ at negative half) and

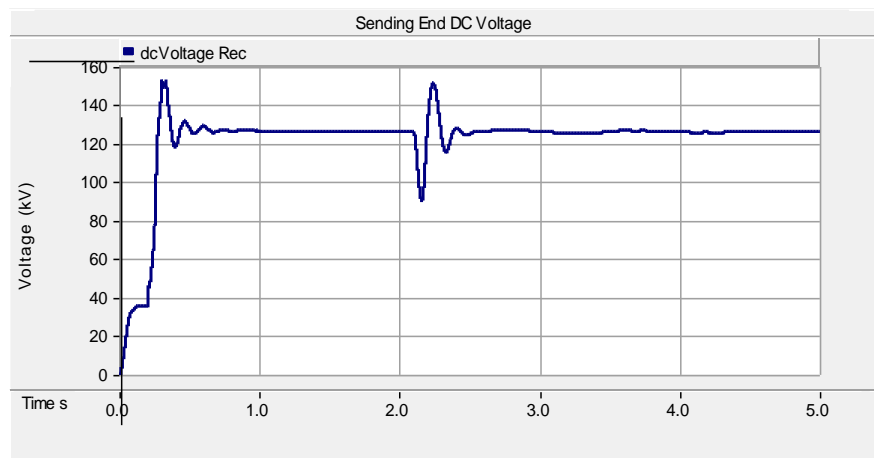

Figure 7.2(d) DC voltage waveform at the time of L-G fault, without STATCOM

In Figure 7.2 (e), with STATCOM, it mitigates the voltage swell largely, in this the value of amplitude is less than the previous one (at about 40 percent i.e., $135 \mathrm{kv}$ at positive half and $90 \mathrm{kv}$ at negative half) and after this fault duration, voltage becomes constant.

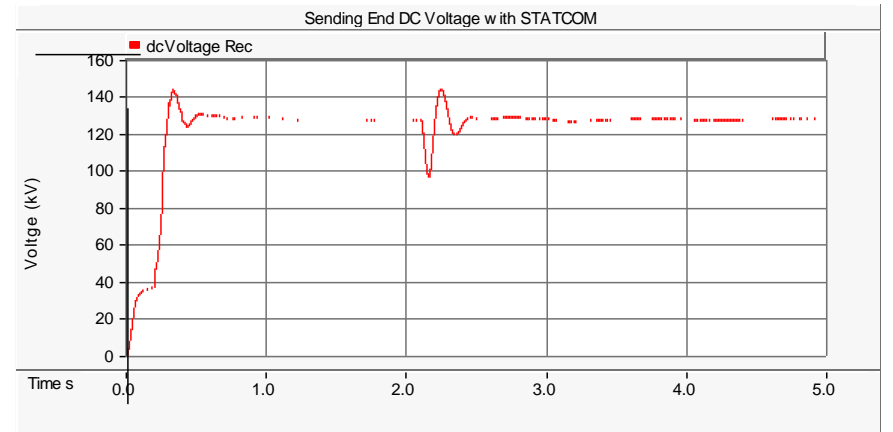

Figure 7.2(e) DC voltage waveform at the time of L-G fault, with STATCOM

In totality from Figure 7.2(f), it is clear that the voltage profile of sending end is approximately same as that of receiving end.

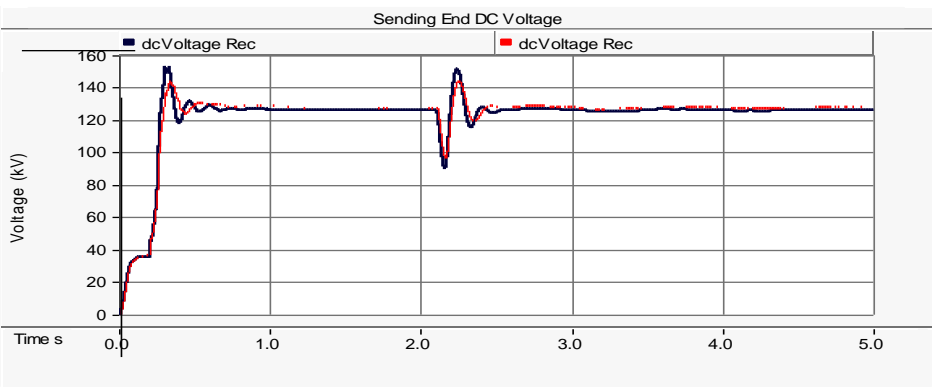

Figure 7.2 (f) DC voltage waveform at the time of L-G fault, with and without STATCOM

b) When Double line to ground fault (LL-G) occurs:

When Double line to ground fault occurs at the receiving end, i.e., at inverter end, then it will greatly affect the line, it is very clearly seen with the help of Figure 7.2(g) without connecting STATCOM at the receiving end. it shows that after some obvious power swing, and fault is occur after 2.1 second, and it is found that voltage dip is very high (i.e.,110 kv below reference )which is of very high amplitude. Green colour shows the receiving end graph of Figure 7.2(g).

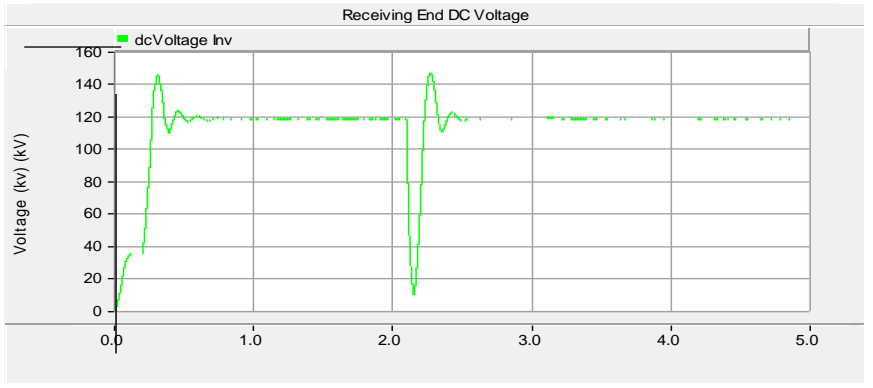

Figure 7.2(g) DC voltage waveform at the time of LL-G fault, without STATCOM

Whereas in case of Figure 7.2 (h) represented by red line, this waveform is obtained by connecting STATCOM at the inverter side of the HVDC system, in this, amplitude is reduced very much.

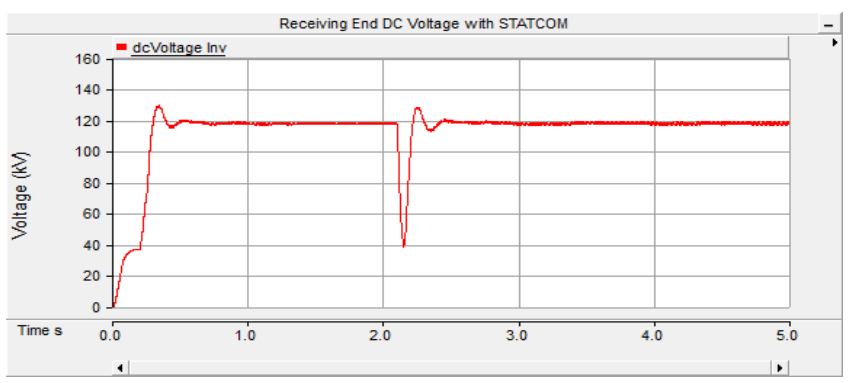

Figure7.2 (h) DC voltage waveform at the time of L L-G fault, with STATCOM 
IOSR Journal of Engineering

May. 2012, Vol. 2(5) pp: 1095-1101

Comparison of without connecting STATCOM i.e., Figure 7.2 (g) and by connecting with STATCOM i.e., Figure 7.2 (h), can be very well seen with the help of Figure 7.2 (i), it shows that after mitigation of STATCOM, the voltage sag, swell is very less. And fault is cleared after 2.5 seconds and system becomes stable.

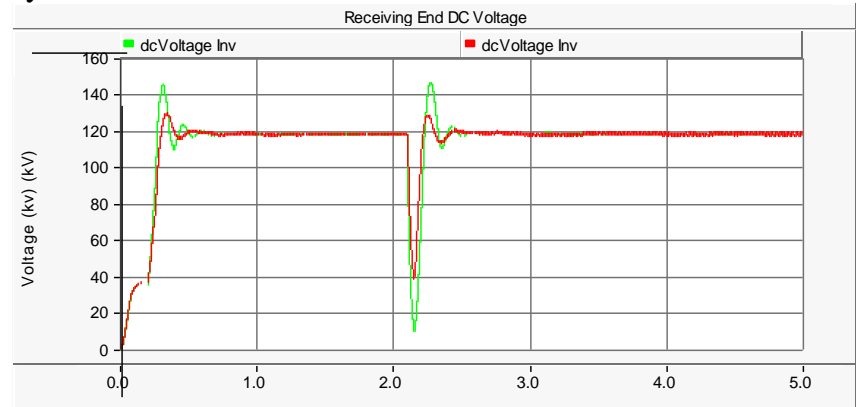

Figure7.2 (i) DC voltage waveform at the time of LL-G fault, with and without STATCOM

\section{Conclusions}

In this paper we have analyzed voltage profile for different cases such as when six pulse transmission line charging, fault Analysis in HVDC line with and without STATCOM at time 2.1 seconds, and faults types are line to ground fault, double line to ground fault and Dc faults. Also considered the effect of power swing on transmission line components such as transformers etc. by using PSCAD/EMTDC [6-7].

This paper describes about the widespread of this project which has enlisted all aspects for High voltage direct current (HVDC) transmission. Good HVDC design begins with a thorough understanding of the basic concepts, their, and operation and control of HVDC system. A good design follows almost from common sense. Certainly, many of the fatal flaws in actual HVDC become obvious when the problem is analyzed in the right way. This dissertation tries to catch attention towards operation and control of HVDC system. There are many bases for operation and control before acting on them, but for High voltage direct current (HVDC) transmission there are many constraints. Hence it is required to test the systems for different condition, and checking the system for limit violations by using features of Power Flow. When systems limits are tested for all cases, evaluation of fault timings where response of $\mathrm{AC}$ and $\mathrm{DC}$ are recorded and studied[8]. In this way efficiently operated and control system could be developed.

\section{REFERENCES}

[1] http://www.scribd.com/doc/86748196/56/Simulationof-Closed-loop-six-pulse-HVDC-system.

[2] Chan-Ki Kim, "Dynamic Coordination Strategies between HVDC and STATCOM", KEPRI (Korea Electric Power Research Institute), Transmission \&
Distribution Conference \& Exposition: Asia and Pacific, vol .18, no.1,oct 2009, Pages: 1-9.

[3] G.Justin Sunil Dhas, "A Novel approach for Voltage Sag Mitigation Using FACTS Device Interline Dynamic Voltage Restorer", Electronics Computer Technology (ICECT), 3rd International Conference, vol.04, no.1. April 2011, Pages: 37- 41.

[4] Narain G.Hingorani \& Laszlo Gyugyi ,"Understanding FACTS Concepts and Technology of Flexible AC Transmission Systems", Power Electronics Los Altos Hills, CA Laszlo Gyugyi Siemens Power Transmission \& Distribution Orlando, FL Mohamed El-Hawary, Consulting Editor. IEEE Press willey Interscience,john willey and sons ,Hoboken ,2000,chapter-5 ,Pages:150205.

[5] M. o. faruque, "Detailed modeling of cigré HVDC benchmark system using pscad / emtdc and Psb /simulink", IEEE transactions on power delivery, vol. 21, no. 1, Jan 2006, Pages: 378-387.

[6] EMTDC/PSCAD Technical documentation, Manitoba HVDC research centre, Canada (trial version of software package available at http s//pscad.com/products/PSCAD/trial download/index.

[7] PSCAD website: http://www.pscad.com

[8] D.T. Oyedokun MIEEE, "Effect of Converter DC fault on the Transient Stability of a MultiMachine Power System with HVDC Transmission lines" IEEE AFRICON Conference, Sept. 2009 vol. 21, no.3, Pages: 1-6. 